\title{
Proteomic profiling of naturally protected extraocular muscles from the dystrophin-deficient mdx mouse
}

\author{
Caroline Lewis, Kay Ohlendieck* \\ Department of Biology, National University of Ireland, Maynooth, Co. Kildare, Ireland
}

\section{A R T I C L E I N F O}

\section{Article history:}

Received 29 April 2010

Available online 22 May 2010

\section{Keywords:}

Extraocular muscle

MDX

Muscular dystrophy

Muscle proteomics

Utrophin

Heat shock protein

\begin{abstract}
A B S T R A C T
Duchenne muscular dystrophy is the most frequent neuromuscular disorder of childhood. Although this Xlinked muscle disease is extremely progressive, not all subtypes of skeletal muscles are affected in the same way. While extremities and trunk muscles are drastically weakened, extraocular muscles are usually spared in Duchenne patients. In order to determine the global protein expression pattern in these naturally protected muscles we have performed a comparative proteomic study of the established mdx mouse model of $x$-linked muscular dystrophy. Fluorescence difference in-gel electrophoretic analysis of 9-week-old dystrophin-deficient versus age-matched normal extraocular muscle, using a pH 4-7 gel range, identified out of 1088 recognized protein spots a moderate expression change in only seven protein species. Desmin, apolipoprotein A-I binding protein and perilipin-3 were found to be increased and gelsolin, gephyrin, transaldolase, and acyl-CoA dehydrogenase were shown to be decreased in mdx extraocular muscles. Immunoblotting revealed a drastic up-regulation of utrophin, comparable levels of $\beta$-dystroglycan and key $\mathrm{Ca}^{2+}$-regulatory elements, and an elevated concentration of small stress proteins in mdx extraocular muscles. This suggests that despite the lack of dystrophin only a limited number of cellular systems are perturbed in mdx extraocular muscles, probably due to the substitution of dystrophin by its autosomal homolog. Utrophin appears to prevent the loss of dystrophin-associated proteins and $\mathrm{Ca}^{2+}$-handling elements in extraocular muscle tissue. Interestingly, the adaptive mechanisms that cause the sparing of extraocular fibers seem to be closely linked to an enhanced cellular stress response.
\end{abstract}

(c) 2010 Elsevier Inc. All rights reserved.

\section{Introduction}

Dystrophinopathies are characterized by a primary deficiency in the Dp427 isoform of the membrane cytoskeletal protein dystrophin [1] and secondary abnormalities in sarcolemmal stability, ion homeostasis, cellular signaling, excitation-contraction coupling, and numerous metabolic pathways [2]. Severely progressive Duchenne muscular dystrophy (DMD) and the more benign Becker muscular dystrophy are allelic muscle diseases and are classified according to changes in the expression level and/or size of dystrophin [3]. The loss in Dp427 triggers the drastic reduction in sarcolemmal glycoproteins, such as sarcoglycans and dystroglycans (DG) which in turn weakens the integrity of the plasmalemma and leads to an increased frequency of membrane rupturing in dystrophic muscle tissues [4]. Since the Dp427-associated glycopro-

Abbreviations: $\alpha \mathrm{BC}, \alpha \mathrm{B}$-crystallin; CSQ, calsequestrin; cvHsp, cardiovascular heat shock protein; DIGE, difference in-gel electrophoresis; DG, dystroglycan; DMD, Duchenne muscular dystrophy; Dp427, dystrophin protein of $427 \mathrm{kDa}$; EOM, extraocular muscle; Hsp, heat shock protein; MS, mass spectrometry; SERCA, sarcoplasmic or endoplasmatic $\mathrm{Ca}^{2+}$-ATPase; Up395, utrophin protein of $395 \mathrm{kDa}$.

* Corresponding author. Fax: +353 (1) 7083845.

E-mail address: kay.ohlendieck@nuim.ie (K. Ohlendieck). tein complex links the extracellular matrix protein laminin and the subsarcolemmal actin membrane cytoskeleton in healthy muscle fibers, the reduced presence of the DG-subcomplex is believed to play a central role in the degeneration of dystrophic muscles. However, not all subtypes of skeletal muscles are affected in the same way in x-linked muscular dystrophy. For example, intrinsic laryngeal and certain distal muscle fibers, as well as extraocular muscle (EOM), are protected from a severely degenerative phenotype in dystrophic organisms [5-11]. Although the contractile efficiency of EOM is weakened in various muscle-related pathologies, such as myasthenia gravis, myasthenic syndromes, botulism, and myotonia congenita [12-14], they are usually spared in DMD patients [15-17].

Therefore, the characterization of these naturally protected muscles may lead to the identification of constitutive properties or adaptive mechanisms that cause the sparing of EOM in dystrophinopathies [17]. The histological, biochemical, and physiological profile of EOM is markedly different from other skeletal muscles [18-21]. During myogenesis, the protein factors responsible for specifying pre-myogenic progenitor cells in EOM seem to be distinct from those in the trunk [22]. EOM represent a unique muscle allotype that controls the movements of the eye. Usually 
fast-twitching muscles are not resistant to fatigue. However, EOM is an exception to this general rule of skeletal muscle physiology. EOM is capable of fast contraction patterns, but is also extremely fatigue-resistance [23]. The coordinated action of six EOMs, i.e. Musculus rectus superior, $M$. rectus inferior, $M$. rectus medial, $M$. rectus lateral, $M$. obliquus superior, and $M$. obliquus inferior, enables the eyeball to move about its vertical, horizontal, and anteroposterior axis. The complex excitation-contraction-relaxation cycle of EOM ranges from slow vergence and pursuit movements to rapid saccades. Hence, based on their unique physiological properties and unusual anatomical structure, many myologists consider EOM as a separate class of skeletal muscles [24].

Since Dp427-deficient EOM does not appear to be affected in a major way, we have carried out a mass spectrometry (MS)-based proteomic comparison of normal versus mdx preparations. The mdx mouse represents an established animal model of DMD, which exhibits severe muscle degeneration in the diaphragm, segmental necrosis in leg muscles, and a mild phenotype in EOM [25]. Proteomic profiling of Dp427-deficient leg and diaphragm muscles has revealed drastic changes in the expression levels of adenylate kinase, the luminal $\mathrm{Ca}^{2+}$-binding protein calsequestrin (CSQ), the cytosolic $\mathrm{Ca}^{2+}$-binding protein regucalcin, and the cardiovascular heat shock protein (cvHsp), as well as a large number of metabolic and contractile muscle proteins, as recently reviewed by Lewis et al. [2]. Here, we have used fluorescence difference in-gel electrophoresis (DIGE), one of the most powerful comparable techniques available in modern biochemistry [26], to study potential changes in protein expression levels in Dp427-deficient versus normal EOM preparations. The identification of only moderate changes in a few select proteins agrees with the notion of a naturally protected phenotype. Importantly, immunoblotting showed an enhanced abundance of stress proteins in mdx EOM, as well as an elevated concentration of the autosomal dystrophin homolog utrophin of $395 \mathrm{kDa}$ (Up395), a comparable density of $\beta$-DG and rescued levels of CSQ. Hence, naturally protected mdx EOM appears to escape fiber degeneration due to Dp427 substitution by Up395 and a prevention of downstream pathophysiological alterations.

\section{Materials and methods}

\subsection{Chemicals and materials}

Chemicals and materials for DIGE analysis were obtained from Amersham Biosciences/GE Healthcare, Little Chalfont, Buckinghamshire, UK. For peptide mass fingerprinting, sequencing grademodified trypsin was purchased from Promega (Madison, WI, USA). Chemiluminescence substrate and protease inhibitors were from Roche Diagnostics (Mannheim, Germany). Primary antibodies were obtained from Cambridge Biosciences, Cambridge, UK, (SPA835 to Hsp90; SPA-801 against Hsp25), HyTest Ltd., Turku, Finland (PCV60 against cvHSP), Sigma Chemical Company, Dorset, UK (pAb L-9393 to laminin), Vision Biosystems Novocastra, Newcastle upon Tyne, UK (NCL-a-BCrys to $\alpha B C$; NCL-b-DG to $\beta$-DG), Thermo Fisher Scientific Inc., Rockford, IL, USA (MA3-913 against CSQ; MA3-912 to SERCA1), Abcam Ltd., Cambridge, UK (ab14730 to mitochondrial ATP synthase) and Santa Cruz Biotechnology, Santa Cruz, CA, USA (sc-15377 to Up395). All secondary antibodies were purchased from Chemicon International (Temecula, CA). All other chemicals used were of analytical grade and purchased from Sigma Chemical Company, Dorset, UK.

\subsection{Dystrophic muscle samples}

The mdx mouse is an established and widely employed animal model of $x$-linked muscular dystrophy with a point mutation in the dystrophin gene [25]. Mildly affected EOM and severely dystrophic diaphragm muscle from male 9-week-old mdx mice and normal tissues from age-matched C57 mice were obtained from the Bioresource Unit of NUI Maynooth [7]. Mice were kept under standard conditions and all procedures were performed in accordance with Irish guidelines on the use of animals for scientific experiments. Animals were sacrificed by cervical dislocation and muscle tissues quickly removed and quick-frozen in liquid nitrogen [27].

\subsection{Preparation of crude muscle extracts}

For the biochemical analysis of crude EOM and diaphragm extracts, three dystrophic and three age-matched normal muscle specimens were pulverized by grinding tissue pieces in liquid nitrogen using a mortar and pestle. Ground muscle was then solubilized in lysis buffer with the ratio of $100 \mathrm{mg}$ wet weight to $1 \mathrm{ml}$ lysis buffer (7 M urea, $2 \mathrm{M}$ thiourea, 4\% CHAPS, 2\% IPG buffer pH4-7, 2\% (w/v) DTT). The lysis buffer contained a freshly prepared protease inhibitor cocktail [27]. EOM protein samples for DIGE analysis were placed in buffer containing only the above listed concentrations of urea, thiourea, and CHAPS. Following gentle rocking for $30 \mathrm{~min}$, suspensions were centrifuged at $4{ }^{\circ} \mathrm{C}$ for $20 \mathrm{~min}$ at $20,000 \mathrm{~g}$ and the protein concentration determined [28].

\subsection{Fluorescence DIGE analysis}

Optimized fluorescence labeling and electrophoretic separation conditions, as recommended by Karp and Lilley [29], were employed to determine potential differences in the expression pattern of the accessible part of the soluble proteome from control versus dystrophic EOM. Labeling was carried out with 200 pmol of Сy3 fluor dye per $25 \mu \mathrm{g}$ protein [26]. An internal pooled standard of every sample was prepared with the Cy5 fluor. Labeled samples were vortexed and incubated for $30 \mathrm{~min}$ on ice in the dark. The reaction was quenched with $10 \mathrm{mM}$ lysine on ice for $10 \mathrm{~min}$ [27]. First dimension isoelectric focusing with $\mathrm{pH}$ 4-7 strips and second dimension slab gel electrophoresis was performed with $50 \mu \mathrm{g}$ protein per gel, as previously described in detail [28].

\subsection{Protein visualization and data analysis}

A Typhoon Trio variable mode imager form Amersham Biosciences/GE Healthcare (Little Chalfont, Bucks., UK) was used to visualize CyDye-labeled EOM proteins. Images of Cy3-labeled muscle proteins were analyzed with Progenesis Samespots software version 3.2.3 from NonLinear Dynamics (Newcastle upon Tyne, UK) and normalized against their corresponding Cy5 image. All gels were then aligned to a master reference image. Following detection of two-dimensional spots, gels were grouped into EOM images versus control images and analyzed to determine significant differences in protein spot density. An ANOVA score of 0.5 was required for spots to be included in the subsequent statistical analysis. All significantly changed spots were visually checked on the aligned gels and then identified by MS analysis.

\subsection{Identification of EOM proteins}

Protein identification via electrospray ionization LC-MS/MS analysis was carried out as recently described in detail [28]. Reference gels were prepared with $400 \mu \mathrm{g}$ of protein and a 1:1 mix of dystrophic to normal muscle complements. Preparative gels were stained with the fluorescent dye Ruthenium II Bathophenanthroline Disulfonate Chelate and two-dimensional protein spots of interest were excised using the automated Ettan spot picker system from Amersham Biosciences (Little Chalfont, Bucks., UK). Protein spots were digested by trypsin [27] and peptide mixtures were 
analyzed on an Agilent 6340 Ion Trap LC mass spectrometer using electrospray ionization (Agilent Technologies, Santa Clara, CA, USA) on a 10 min gradient of $5-100 \%$ acetonitrile/ $0.1 \%$ formic acid with a post run of $1 \mathrm{~min}$ [28]. Separation of peptides was performed with a nanoflow Agilent 1200 series system, equipped with a Zorbax $300 S B$ C18 $\mu \mathrm{m}, 4 \mathrm{~mm} 40 \mathrm{nl}$ pre-column. Mobile phases used were (A) $0.1 \%$ formic acid, (B) $50 \%$ acetonitrile and $0.1 \%$ formic acid. Samples $(8 \mu \mathrm{l})$ were loaded onto the enrichment column with capillary flow rate set at $4 \mu \mathrm{l} / \mathrm{min}$ with a mix of $A: B$ at a ratio of $19: 1$. Elution was carried out with the nano pump flow rate set at $0.6 \mu \mathrm{l} / \mathrm{min}$. Database searches were carried out using Mascot MS/MS Ion search. Criterion for each search was set at (i) species Mus musculus, (ii) two missed cleavages by trypsin, (iii) variable modification: oxidation of methionine, (iv) fixed modification: carboxymethylation of cysteines, and (v) mass tolerance of precursor ions $\pm 2 \mathrm{Da}$ and product ions \pm 1 Da [28].

\subsection{Immunoblot analysis}

One-dimensional immunoblotting was used to determine the fate of select EOM and diaphragm proteins in the mdx animal model. Gel electrophoretic separation and transfer was carried out with a Mini-Protean II electrophoresis and transfer system from Bio-Rad Laboratories (Hemel-Hempstead, Herts, UK). Muscle proteins were transferred to nitrocellulose for $70 \mathrm{~min}$ at $100 \mathrm{~V}$ and at $4{ }^{\circ} \mathrm{C}$. Blocking of membranes was achieved with a milk protein solution (5\% $(\mathrm{w} / \mathrm{v})$ fat-free milk powder in $0.9 \%(\mathrm{w} / \mathrm{v}) \mathrm{NaCl}, 50 \mathrm{mM}$ sodium phosphate, $\mathrm{pH}$ 7.4) for $1 \mathrm{~h}$. Incubation with sufficiently diluted primary antibody was carried out overnight with gentle agitation. Nitrocellulose sheets were washed and then incubated for $1 \mathrm{~h}$ with secondary peroxidase-conjugated antibodies, diluted in blocking solution [27]. Immuno-decorated bands were visualized using chemiluminescence substrate (Roche Diagnostics, Mannheim, Germany). Densitometric scanning of immunoblots was performed using ImageJ (NIH).

\section{Results}

Since EOM tissues exhibit a uniquely mild phenotype in an otherwise dystrophic organism, we performed a comparative proteomic analysis of normal versus mdx preparations. For the optimized DIGE analysis of normal versus mdx extracts from EOM, we have followed the recommendations of Karp and Lilley [29]. Fig. 1 illustrates representative two-dimensional gels of Cy3-labeled normal and dystrophic EOM tissue and corresponding Cy5-labeled pooled standards.

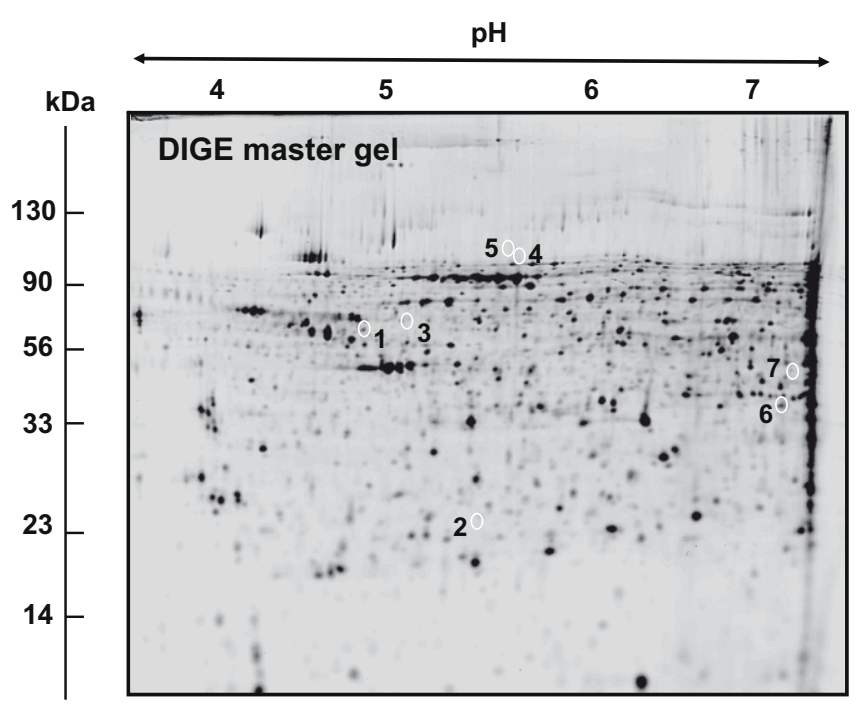

Fig. 2. DIGE analysis of mdx EOM tissue. Shown is a Cy5-labeled master gel of crude tissue extracts from EOM tissue covering the $\mathrm{pH}$ 4-7 range. Protein spots with a moderately changed expression in mdx preparations are marked by circles and are numbered 1-7. See Table 1 for a detailed listing of these EOM-associated proteins with a changed abundance in the mdx mouse. The $\mathrm{pH}$-values of the first dimension gel system and molecular-mass standards (in $\mathrm{kDa}$ ) of the second dimension are indicated on the top and on the left of the panels, respectively.
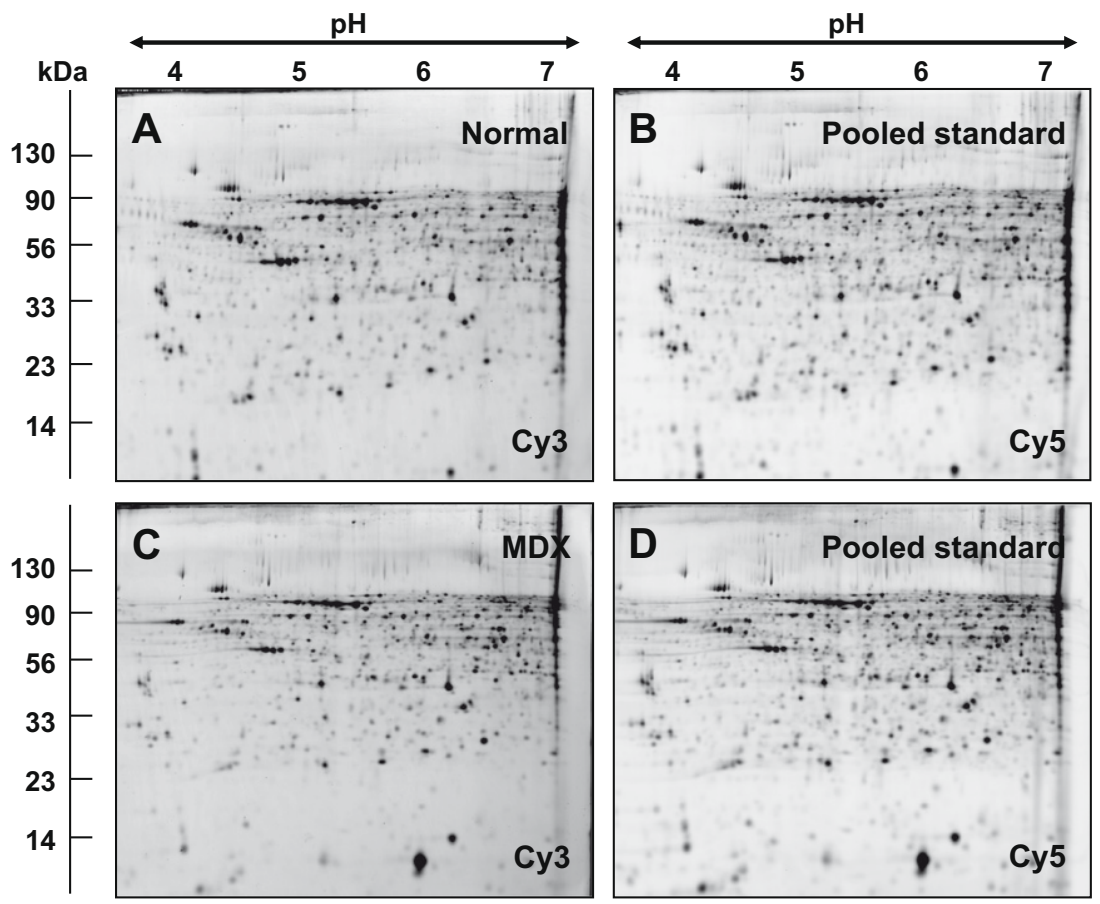

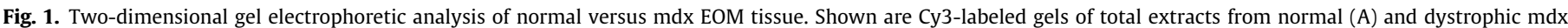

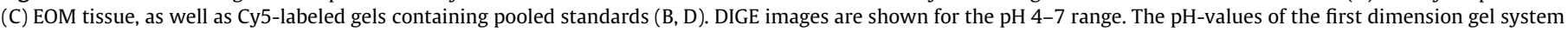
and molecular-mass standards (in $\mathrm{kDa}$ ) of the second dimension are indicated on the top and on the left of the panels, respectively. 
Gel electrophoretically separated protein spots were analyzed with the help of a Typhoon Trio variable imager and Progenesis 2-D analysis software. Overall, 1088 distinct muscle protein species were recognized in slab gels with an isoelectric focusing range of $\mathrm{pH} 4-$ 7. We employed this $\mathrm{pH}$-range in the first dimensional separation step since previous gel electrophoretic studies have identified the majority of muscle proteins in this region [2].

An analytical master gel is shown in Fig. 2. Moderate expression changes were found in seven protein species. These muscle-associated proteins are marked and numbered 1-7 in the Cy5-labeled gel, so that it is possible to correlate MS-identified protein species, listed in Table 1, with distinct two-dimensional spots of altered density in mdx EOM preparations. Electrospray ionization LC-MS/MS analysis was performed to unequivocally identify the changed EOM-associated proteins. The information listed in Table 1 lists the spot number, protein name, protein ID, number of matched peptides, matched peptide sequences, percentage se- quence coverage, the relative molecular mass, $\mathrm{pI}$-value, Mascot score, and fold change of individual proteins affected by deficiency in Dp427. MS analysis identified the increased proteins as the muscle-specific intermediate filament protein desmin (spot 1 ), apolipoprotein A-I binding protein (spot 2) and perilipin-3 (spot 3 ) and the decreased proteins as cytosolic gelsolin (spot 4), gephyrin (spot 5), transaldolase (spot 6), and acyl-CoA dehydrogenase (spot 7).

In order to further characterize the EOM phenotype, comparative immunoblotting was carried out. The immunoblot analysis shown in Fig. 3 revealed a drastic up-regulation of Up395, comparable levels of $\beta$-DG and CSQ, and an elevated concentration of stress proteins in mdx EOM preparations. Immuno-decoration experiments clearly illustrated that the expression of the dystrophin-associated glycoprotein $\beta$-DG is drastically reduced in the severely degenerative mdx diaphragm, but of comparable levels in mdx EOM tissue (Fig. 3D and E). The same is true for the luminal ion-binding protein CSQ (Fig. 3J and $\mathrm{K}$ ). The concentration of the

Table 1

List of DIGE-identified proteins with a changed abundance in 9-week-old extraocular muscle from the MDX mouse model of Duchenne muscular dystrophy.

\begin{tabular}{|c|c|c|c|c|c|c|c|c|c|}
\hline $\begin{array}{l}\text { Spot } \\
\text { No. }\end{array}$ & Protein name & Matched peptide sequence & $\begin{array}{l}\text { Protein } \\
\text { Accession No. }\end{array}$ & $\begin{array}{l}\text { Peptides } \\
\text { matched }\end{array}$ & $\begin{array}{l}\% \\
\text { Coverage }\end{array}$ & $\begin{array}{l}\text { Molecular } \\
\text { mass (kDa) }\end{array}$ & $\begin{array}{l}\text { Isoelectric } \\
\text { point }(\mathrm{p} I)\end{array}$ & $\begin{array}{l}\text { Mascot } \\
\text { score }\end{array}$ & $\begin{array}{l}\text { Fold } \\
\text { change }\end{array}$ \\
\hline 1 & $\begin{array}{l}\text { Desmin, muscle-specific } \\
\text { intermediate filament }\end{array}$ & $\begin{array}{l}\text { FASEANGYQDNIAR } \\
\text { LLEGEESR }\end{array}$ & gi|33563250| & 2 & 4 & 53.5 & 5.2 & 51 & +2.1 \\
\hline 2 & $\begin{array}{l}\text { Apolipoprotein A-I binding } \\
\text { protein }\end{array}$ & $\begin{array}{l}\text { AYPPTSMSK } \\
\text { LFGYQPTIYYPK } \\
\text { RPNKPLFTGLVTQCQK } \\
\text { EPFHSILSVLSGLTVPIASIDIPSGWDVEK } \\
\text { GNPSGIQPDLLISLTAPK }\end{array}$ & gi|21553309| & 5 & 30 & 31.3 & 7.6 & 65 & +1.8 \\
\hline 3 & Perilipin-3 & $\begin{array}{l}\text { TLTTAAVSTAQPILSK } \\
\text { LEPQIATASEYAHR } \\
\text { SAMTSGVQSVMGSR } \\
\text { VGQMVISGVDR } \\
\text { AQETLQQLTSVLGLMESVK } \\
\text { TPQDAEKDPAKPEQVEAR }\end{array}$ & gi|13385312| & 6 & 21 & 47.3 & 5.4 & 204 & +1.5 \\
\hline 4 & Gelsolin, cytosolic & DSQEEEKTEALTSAK & gi|90508| & 1 & 2 & 81.1 & 5.5 & 92 & -1.4 \\
\hline 5 & Gephyrin & $\begin{array}{l}\text { GSQECFQFILPALPHAIDLLR } \\
\text { DTASLSTTPSESPR } \\
\text { LSTASCPTPK } \\
\text { AFITVLEMTPVLGTEIINYR } \\
\text { VLAQDVYAK } \\
\text { GEVVDVMVIGR }\end{array}$ & gi|148670669| & 6 & 11 & 82.0 & 5.4 & 139 & -1.7 \\
\hline 6 & Transaldolase & $\begin{array}{l}\text { MESALDQLK } \\
\text { LGGPQEEQIK } \\
\text { LFVLFGAEILK } \\
\text { LSFDKDAMVAR } \\
\text { RLIELYK } \\
\text { LIELYK } \\
\text { LSSTWEGIQAGK } \\
\text { ILDWHVANTDKK } \\
\text { SYEPQEDPGVK } \\
\text { TIVMGASFR } \\
\text { ALAGCDFLTISPK } \\
\text { LLGELLK }\end{array}$ & gi|33859640| & 12 & 33 & 37.5 & 6.6 & 147 & -1.8 \\
\hline 7 & Acyl-CoA dehydrogenase & $\begin{array}{l}\text { KLTDIGIR } \\
\text { IFSSEHDIFR } \\
\text { KFFQEEVIPHHTEWEK } \\
\text { FFQEEVIPHHTEWEK } \\
\text { QGLLGINIAEK } \\
\text { FIPQMTAGK } \\
\text { SGSDWILNGSK } \\
\text { VFITNGWLSDLVIVVAVTNR } \\
\text { SPAHGISLFLVENGMK } \\
\text { AQDTAELFFEDVR } \\
\text { LPANALLGEENK } \\
\text { GFYYLMQELPQER } \\
\text { LLIAELAISACEFMFEETR } \\
\text { TVAHIQTVQHK } \\
\text { AFVDSCLQLHETK } \\
\text { VQPIYGGTNEIMK }\end{array}$ & gi|31982520| & 16 & 45 & 48.3 & 8.3 & 321 & -1.9 \\
\hline
\end{tabular}




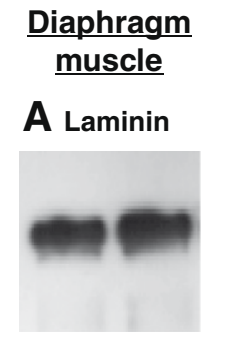

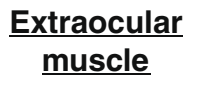

$$
\frac{\text { Extraocular }}{\text { muscle }}
$$

B Laminin
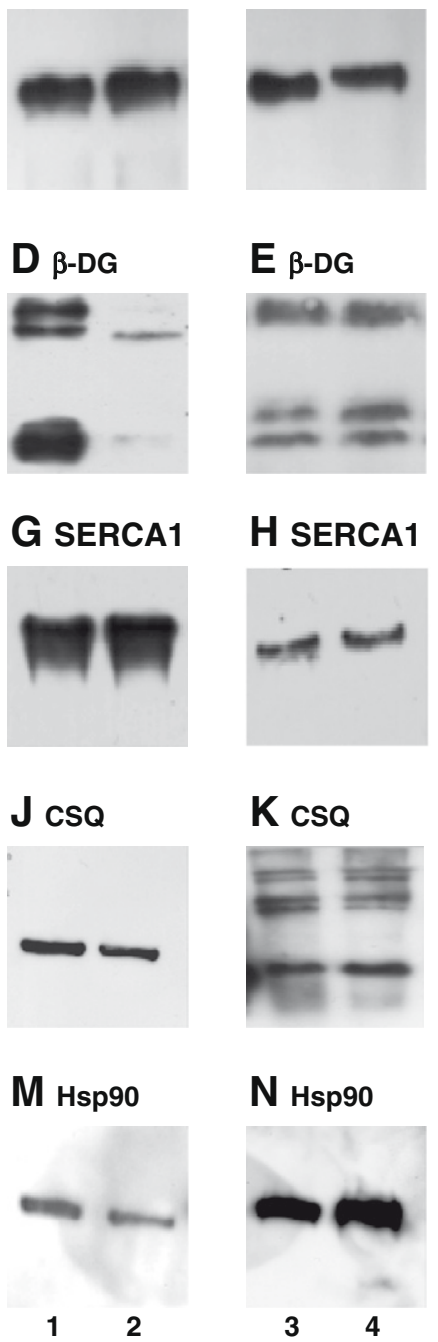
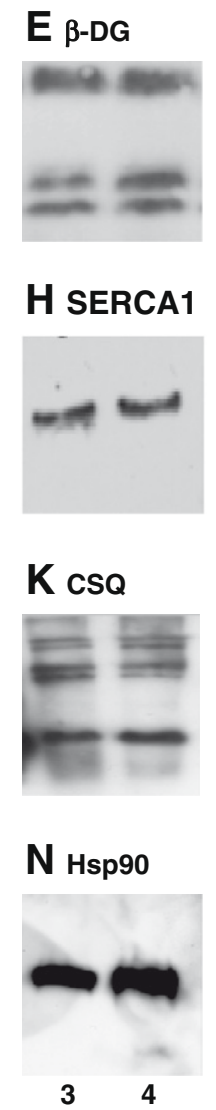
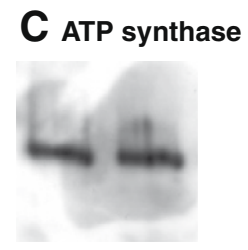

F Up395

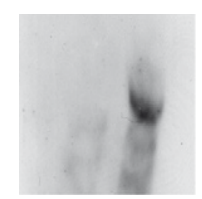

I $\alpha B C$

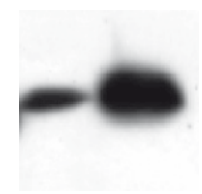

L cvHsp

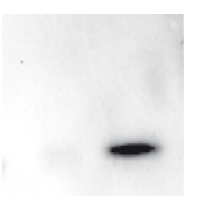

Hsp25

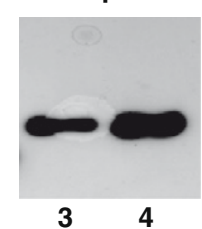

Fig. 3. Immunoblotting survey of mdx EOM tissue. Shown are representative immunoblots with expanded views of immuno-decorated bands labeled with antibodies to laminin (A, B), ATP synthase (C), $\beta$-DG (D, E), Up395 (F), SERCA1 (G, H), $\alpha B C(\mathrm{I}), \mathrm{CSQ}(\mathrm{J}, \mathrm{K}), \mathrm{cvHsp}(\mathrm{L}), \mathrm{Hsp} 90(\mathrm{M}, \mathrm{N})$, and Hsp25 (O). Lanes 3 and 4 represent normal and mdx EOM preparations, respectively. For comparative purposes, lanes 1 and 2 show normal versus mdx diaphragm preparations, respectively.

extracellular matrix component laminin, ATP synthase and the SERCA1 pump appear not to be changed in a major way in $\mathrm{mdx}$ mice (Fig. 3A-C, G and H). Immunolabeling of the Up395 isoform of utrophin confirmed the results of previous studies and showed a marked increase of this autosomal homolog of Dp427 in EOM (Fig. 3F). An immunoblotting survey of key stress proteins demonstrated a drastic increase of essential Hsp elements in mildly dystrophic EOM preparations. The expression of the small stress proteins Hsp25, $\alpha \mathrm{B}$-crystallin $(\alpha \mathrm{BC})$ and cvHsp was elevated in Dp427-deficient EOM tissue (Fig. 3F-I, L and O). In contrast to decreased levels of Hsp90 in the dystrophic diaphragm, this large stress protein was shown to be increased in mdx EOM (Fig. 3M and $\mathrm{N}$ ).

\section{Discussion}

As compared to non-fluorescent protein dye approaches, the application of fluorescent CyDyes has decisively improved the dynamic range of protein coverage in comparative proteomic studies $[26,29]$. We have therefore used the highly accurate quantitative DIGE technique for the analysis of the mildly affected EOM from the mdx model of DMD. In other subtypes of skeletal muscles, the deficiency in Dp427 causes drastic downstream alterations [2]. Proteomic studies have clearly established a generally perturbed protein expression pattern in mdx diaphragm muscle [27]. It is therefore crucial to employ an extremely sensitive biochemical method in order to be able to detect minor changes in a naturally protected phenotype of dystrophinopathy. Since the fluorescent DIGE technique enables multiple protein samples to be separated on the same two-dimensional gel, potential artifacts due to gelto-gel variations are greatly reduced [26]. Hence, DIGE analysis suggests itself as an ideal analytical tool to conduct a comparative investigation into the proteomic changes in mdx EOM versus normal EOM preparations. The proteomic findings presented here agree with the idea that EOM tissue is only marginally affected by the loss in Dp427.

A moderate change in abundance in seven EOM-associated proteins, as shown here by DIGE analysis, is in stark contrast to major alterations in 35 diaphragm proteins, as previously shown by MSbased studies [2,27]. The approximately 2-fold increase in musclespecific desmin is an interesting finding, since it supports the hypothesis that the loss in Dp427 is partially compensated in EOM tissue by strengthening the intermediate filament network. High levels of desmin might stabilize the small diameter EOM fibers and thereby protect them from extensive contraction-induced injury in the absence of Dp427. The higher concentration of apolipoprotein A-I binding protein and perilipin-3 suggests an increased utilization of lipid metabolism. Apolipoprotein A-I binding protein interacts with apolipoprotein A-I, a crucial constituent of high-density lipoprotein, and is involved in cholesterol efflux mechanisms. Perilipin-3 is a lipid droplet-associated protein that functions as a protective coating against lipases. An increased level of both proteins might support the altered metabolic needs of Dp427-deficient EOM fibers. The decreased levels of gelsolin, gephyrin, transaldolase, and acyl-CoA dehydrogenase have probably an effect on structural and metabolic mechanisms. Gelsolin is an actin-binding element that regulates actin filament dynamics and gephyrin is a tubulinbinding protein involved in clustering of glycinergic and GABAergic receptors. Hence, a reduced density in these two binding proteins might affect actin-based cytoskeletal stability and trigger a certain degree of post-synaptic disturbances in Dp427-deficient EOM fibers. Lower levels of transaldolase and acyl-CoA dehydrogenase indicate moderate changes in metabolite utilization. Transaldolase represents a non-oxidative enzyme of the pentose phosphate pathway and links this metabolic system to glycolysis. Acyl-CoA dehydrogenase is a crucial mitochondrial enzyme involved in fatty acid metabolism. Decreased densities of these two enzymes might therefore impair key metabolic processes, including the glycolytic pathway, and fatty acid $\beta$-oxidation.

In contrast to the above discussed moderate changes in structural and metabolic elements as determined by DIGE analysis, immunoblotting demonstrated on the one hand the rescue of key muscle proteins in mdx EOM and on the other hand a drastic upregulation of proteins belonging to the hsp family of molecular chaperones. These alterations were probably not detected by proteomics due to the low abundance of these proteins in conventional two-dimensional gels. Interestingly, the drastic increase in Up395 in Dp427-deficient EOM tissue is associated with comparable levels of the crucial dystrophin-associated glycoprotein $\beta$-DG and the luminal $\mathrm{Ca}^{2+}$-binding protein CSQ. Both proteins are greatly reduced in the dystrophic diaphragm and are believed to be major pathophysiological factors in $\operatorname{DMD}[2,30]$. The secondary loss in $\beta$-DG causes the disintegration of sarcolemmal stability and subsequent $\mathrm{Ca}^{2+}$-dependent necrotic changes in muscular 
dystrophy. Low levels of CSQ seem to exacerbate abnormal cytosolic $\mathrm{Ca}^{2+}$-handling by impairing luminal $\mathrm{Ca}^{2+}$-buffering in the dystrophic sarcoplasmic reticulum. These pathological alterations appear not to be present in mdx EOM tissue [31], which agrees with the previously reported resistance of dystrophic EOM fibers to $\mathrm{Ca}^{2+}$-induced muscle degeneration [15].

The drastic increase in molecular chaperones suggests that $\mathrm{mdx}$ EOM is capable of sustained cellular stress responses, involving both low- and high-molecular-mass Hsp elements. Since small Hsps are especially associated with the repair of the cytoskeletal network in skeletal muscle [2], the up-regulation of Hsp25, $\alpha B C$, and cvHsp might be linked to the DIGE-determined increase in desmin. In general, stress proteins facilitate the stabilization or elimination of misfolded proteins or peptide clusters in order to prevent the deleterious accumulation of non-functional protein aggregates. Chaperone activity probably plays an important role in the rescue mechanisms that are intrinsic to EOM fibers.

In conclusion, this proteomic and biochemical study clearly showed that the mild phenotype of mdx EOM is associated with (i) only a limited number of metabolic and structural systems being perturbed, (ii) a drastic increase in Up395 and a concomitant rescue of sarcolemmal $\beta$-DG, (iii) comparable levels of key $\mathrm{Ca}^{2+}$-handling proteins, and (iv) a drastic increase in molecular chaperones. Thus, the up-regulation of Hsps and the rescue of the luminal $\mathrm{Ca}^{2+}$-uptake apparatus in mdx EOM tissue, as well as the extra-junctional expression of Up395, are probably crucial for preventing severe muscular dystrophy. This makes these proteins potential pharmacological targets for the development of future therapies to treat DMD. In addition, the small diameter and limited load bearing of EOM fibers might also be critical factors that render this subtype of skeletal muscle extremely resistant to cellular degeneration.

\section{Acknowledgments}

Research was supported by a project grant from Muscular Dystrophy Ireland, a postgraduate stipend from the Irish Research Council for Science, Engineering and Technology, and a Hume scholarship from NUI Maynooth, as well as equipment grants from the Irish Health Research Board and the Higher Education Authority.

\section{References}

[1] A.H. Ahn, L.M. Kunkel, The structural and functional diversity of dystrophin, Nat. Genet. 3 (1993) 283-291.

[2] C. Lewis, S. Carberry, K. Ohlendieck, Proteomic profiling of x-linked muscular dystrophy, J. Muscle Res. Cell Motil. 30 (2009) 267-269.

[3] K.F. O'Brien, L.M. Kunkel, Dystrophin and muscular dystrophy: past, present and future, Mol. Genet. Metab. 74 (2001) 75-88.

[4] C.D. Cohn, K.P. Campbell, Molecular basis of muscular dystrophies, Muscle Nerve 23 (2000) 1456-1471.

[5] P. Dowling, K. Culligan, K. Ohlendieck, Distal mdx muscle groups exhibiting up-regulation of utrophin and rescue of dystrophin-associated glycoproteins exemplify a protected phenotype in muscular dystrophy, Naturwissenschaften 89 (2002) 75-78.

[6] J.D. Porter, A.P. Merriam, S. Khanna, F.H. Andrade, C.R. Richmonds, P. Leahy, G. Cheng, P. Karathanasis, X. Zhou, L.L. Kusner, M.E. Adams, M. Willem, U. Mayer, H.J. Kaminski, Constitutive properties, not molecular adaptations, mediate extraocular muscle sparing in dystrophic mdx mice, FASEB J. 17 (2003) 893-895.

[7] P. Dowling, J. Lohan, K. Ohlendieck, Comparative analysis of Dp427-deficient mdx tissues shows that the milder dystrophic phenotype of extraocular and toe muscle fibres is associated with a persistent expression of betadystroglycan, Eur. J. Cell Biol. 82 (2003) 222-230.

[8] J.D. Porter, A.P. Merriam, P. Leahy, B. Gong, S. Khanna, Dissection of temporal gene expression signatures of affected and spared muscle groups in dystrophin-deficient (mdx) mice, Hum. Mol. Genet. 12 (2003) 1813-1821.

[9] G.M. Smythe, Dystrophic pathology in the intrinsic and extrinsic laryngeal muscles in the mdx mouse, J. Otolaryngol. Head Neck Surg. 38 (2009) 323-336.

[10] M.J. Marques, A. Pertille, C.L. Carvalho, H.S. Neto, Acetylcholine receptor organization at the dystrophic extraocular muscle neuromuscular junction, Anat. Rec. 290 (2007) 846-854.

[11] M.J. Marques, R. Ferretti, V.U. Vomero, E. Minatel, H.S. Neto, Intrinsic laryngeal muscles are spared from myonecrosis in the mdx mouse model of Duchenne muscular dystrophy, Muscle Nerve 35 (2007) 349-353.

[12] M. Cleary, G.J. Williams, R.A. Metcalfe, The pattern of extra-ocular muscle involvement in ocular myasthenia, Strabismus 16 (2008) 11-18.

[13] J.S. Stahl, L. Averbuch-Heller, B.F. Remler, R.J. Leigh, Clinical evidence of extraocular muscle fiber-type specificity of botulinum toxin, Neurology 51 (1998) 1093-1099.

[14] B. Wakeman, D. Babu, J. Tarleton, I.M. Macdonald, Extraocular muscle hypertrophy in myotonia congenita, J. AAPOS 12 (2008) 294-296.

[15] T.S. Khurana, R.A. Prendergast, H.S. Alameddine, F.M. Tome, M. Fardeau, K. Arahata, H. Sugita, L.M. Kunkel, Absence of extraocular muscle pathology in Duchenne's muscular dystrophy: role for calcium homeostasis in extraocular muscle sparing, J. Exp. Med. 182 (1995) 467-475.

[16] J.D. Porter, R.S. Baker, Muscles of a different 'color': the unusual properties of the extraocular muscles may predispose or protect them in neurogenic and myogenic disease, Neurology 46 (1996) 30-37.

[17] F.H. Andrade, J.D. Porter, H.J. Kaminiski, Eye muscle sparing by the muscular dystrophies: lessons to be learned?, Microsc Res. Tech. 48 (2000) 192-203.

[18] M.D. Fischer, M.T. Budak, M. Bakay, J.R. Gorospe, D. Kjellgren, F. PedrosaDomellof, E.P. Hoffman, T.S. Khurana, Definition of the unique human extraocular muscle allotype by expression profiling, Physiol. Genomics 22 (2005) 283-291

[19] D. Kjellgren, M. Ryan, K. Ohlendieck, L.E. Thornell, F. Pedrosa-Domellof, Sarco(endo)plasmic reticulum $\mathrm{Ca}^{2+}$ ATPases (SERCA-1 and -2) in human extraocular muscles, Invest. Ophthalmol. Vis. Sci. 44 (2003) 5057-5062.

[20] K.B. Stirn, V. Smerdu, I. Erzen, Histochemical and immunohistochemical profile of human and rat ocular medial rectus muscles, Graefes Arch. Clin. Exp. Ophthalmol. 247 (2009) 1505-1515.

[21] A.C. Rossi, C. Mammucari, C. Argentini, C. Reggiani, S. Schiaffino, Two novel/ ancient myosins in mammalian skeletal muscles: MYH14/7b and MYH15 are expressed in extraocular muscles and muscle spindles, J. Physiol. 588 (2010) 353-364.

[22] R. Sambasivan, B. Gayraud-Morel, G. Dumas, C. Cimper, S. Paisant, R.G. Kelly, S. Tajbakhsh, Distinct regulatory cascades govern extraocular and pharyngeal arch muscle progenitor cell fates, Dev. Cell 16 (2009) 810-821.

[23] S. Martinez-Conde, S.L. Macknik, Fixational eye movements across vertebrates: comparative dynamics, physiology, and perception, J. Vis. 8 (2008) 28.1-28.16.

[24] J.D. Porter, Extraocular muscle: cellular adaptations for a diverse functional repertoire, Ann. N. Y. Acad. Sci. 956 (2002) 7-16.

[25] M. Durbeej, K.P. Campbell, Muscular dystrophies involving the dystrophinglycoprotein complex: an overview of current mouse models, Curr. Opin. Genet. Dev. 12 (2002) 349-361.

[26] S. Viswanathan, M. Unlu, J.S. Minden, Two-dimensional difference gel electrophoresis, Nat. Protoc. 1 (2006) 1351-1358.

[27] P. Doran, G. Martin, P. Dowling, H. Jockusch, K. Ohlendieck, Proteome analysis of the dystrophin-deficient MDX diaphragm reveals a drastic increase in the heat shock protein cvHSP, Proteomics 6 (2006) 4610-4621.

[28] C. Lewis, H. Jockusch, K. Ohlendieck, Proteomic profiling of the dystrophindeficient MDX heart reveals drastically altered levels of key metabolic and contractile proteins, J. Biomed. Biotechnol., in press.

[29] N.A. Karp, K.S. Lilley, Maximising sensitivity for detecting changes in protein expression: experimental design using minimal CyDyes, Proteomics 5 (2005) 3105-3115.

[30] A. Pertille, C.L. de Carvalho, C.Y. Matsumura, H.S. Neto, M.J. Marques, Calciumbinding proteins in skeletal muscles of the mdx mice: potential role in the pathogenesis of Duchenne muscular dystrophy, Int. J. Exp. Pathol. 91 (2010) 63-71.

[31] R. Ferretti, M.J. Marques, A. Pertille, H.S. Neto, Sarcoplasmic-endoplasmicreticulum $\mathrm{Ca}^{2+}$-ATPase and calsequestrin are overexpressed in spared intrinsic laryngeal muscles of dystrophin-deficient mdx mice, Muscle Nerve 39 (2009) 609-615. 